\title{
Recurrent preeclampsia and breech presentation in term pregnancy: the case of didelphic uterus
}

\section{Temesgen Tilahun Bekabil*}

\begin{abstract}
Assistant Professor of Obstetrics \& Gynaecology, collage of Medical and Health Sciences, Wollega University, Nekemte, Wollega, Ethiopia
\end{abstract}

Received: 06 March 2015

Accepted: 19 April 2015

\section{*Correspondence: \\ Dr. Temesgen Tilahun Bekabil, \\ E-mail: ttamuko@yahoo.com}

Copyright: $\odot$ the author(s), publisher and licensee Medip Academy. This is an open-access article distributed under the terms of the Creative Commons Attribution Non-Commercial License, which permits unrestricted non-commercial use, distribution, and reproduction in any medium, provided the original work is properly cited.

\begin{abstract}
Uterine didelphys represents a uterine malformation where the uterus is present as a paired organ. It is characterized by the presence of two endometrial cavities, each with a uterine cervix, and often a double or single vagina as well. Uterine didelphys, like other uterine malformations, is often asymptomatic and therefore remain unrecognized. The didelphic uterus has a poor reproductive outcome with a 20-30\% chance of carrying pregnancy to term. I report a case of successful pregnancy in the left sided uterine body of a didelphic uterus which was complicated by recurrent preeclampsia and breech presentation. The case also demonstrates how didelphic uterus sometimes remains unrecognized until delivery. In conclusion, it is important to have high index of suspicion of didelphic uterus when term pregnancy is complicated by recurrent breech presentation.
\end{abstract}

Keywords: Uterine didelphys, Didelphic uterus, Breech presentation, Preeclampsia

\section{INTRODUCTION}

Congenital uterine anomalies are malformations of uterus that develop due to disturbances in development, formation or fusion of Mullerian ducts during embryonic life. $^{1,2}$ They are often asymptomatic and therefore unrecognized. They may affect a young woman due to pain at the time of menarche, or a woman's obstetric and/or gynecologic health. ${ }^{3}$ The prevalence rate of uterine malformations in general fertile population is 0.001 to $10 \%$, in infertile population it is $3.5 \%$ and in patients with recurrent miscarriage it is $13 \%$. $^{3,4}$

A didelphic uterus results when there is failed fusion of the paired Müllerian ducts. This anomaly is characterized by the presence of two endometrial cavities, each with a uterine cervix. Individual horns are fully developed and normal in size. Each hemiuteri is associated with one fallopian tube. A longitudinal or transverse vaginal septum may be noted. The vagina may be single or double. ${ }^{5,6}$

Uterus didelphys is associated with developmental urinary tract abnormalities. Therefore, all women with müllerian defects should undergo a radiologic renal investigation, such as an intravenous pyelogram or renal ultrasound. ${ }^{6-8}$

The incidence of uterine didelphys varies from 1 in 1500 to 1 in 42000 pregnancies worldwide. It can result in obstetrical complications, such as spontaneous abortion, preterm labor, cervical incompetence and malpresentation. ${ }^{6,8}$ It has a poor reproductive outcome with a $20-30 \%$ chance of carrying pregnancy to term. Didelphic uterus can be considered in cases of severe dysmenorrhoea, chronic pelvic pain, a symptomatic or asymptomatic pelvic mass that is inseparable from the uterus. ${ }^{9}$ 
Clinical presentation of didelphic uterus can vary from asymptomatic to grave obstetrics and gynecologic complications imposing difficulties in management for the attending obstetricians and gynecologists. Here, I present the case of didelphic uterus at term pregnancy complicated by recurrent breech presentation and preeclampsia.

\section{CASE REPORT}

A 22 year old gravid II para I mother whose gestational age by date from reliable last normal menstrual period was 38 weeks and 3 days presented to the hospital after she was referred from health center with active labor, breech presentation and severe preeclampsia. She was laboring at health center for 8 hours. She passed liquor 3 hours back. At presentation she was complaining headache for the last 2 days.

Her antenatal care (ANC) was at private clinic where she was diagnosed to have severe preeclampsia and was on aldomet $250 \mathrm{mg}$ per os daily for the last one month. During her ANC follow up, she had ultrasound examination twice both of which reported breech presentation and normal fetal biometry but no other uterine mass or pathology identified.

Her previous delivery was 3 years back in this hospital. It was breech presentation and she delivered female alive neonate by assisted breech delivery. She had also preeclampsia during that time.

She reported menarche at the age of 13 years. Her menses was regular and there was no dysmenorrhea or dyspareunia.

On examination, her vital signs were $\mathrm{BP}=160 / 110$ $\mathrm{mmHg}, \mathrm{PR}=100$ beats per minute, $\mathrm{RR}=26$ breaths per minute $\& \mathrm{~T}=36.8$ degree Celsius. She had pink conjunctivae and non-icteric sclera. On Leopold maneuver, the uterus was term sized, breech presentation and FHB ranges from 117-130 beats per minute. There were 3 uterine contractions in 10 minutes each lasting for 30 to 40 seconds. There was 14 weeks sized right side smooth mass next to the uterus which seems to arise from the pelvis. On digital pelvic examination, cervix was 4 $\mathrm{cm}$ dilated and it was footling breech presentation.

Laboratory examination showed blood group $\mathrm{O}+$, normal complete blood count parameters, proteinuria of $3+$ on urinalysis, and normal renal and liver function tests.

After the admission, her blood pressure was controlled with two doses of hydralazine $5 \mathrm{mg}$ IV given 20 minutes apart and $30 \mathrm{mg}$ diazepam in $1000 \mathrm{ml}$ saline at 30 drops per minute started for eclampsia prophylaxis.

With the impression of footling breech presentation and severe preeclampsia, she was prepared for cesarean section. Upon entering the abdomen, there were two separate uteri each having one ovary and tube (Figure 1). The smaller one was on the right side, soft and 14 weeks sized. Lower uterine segment was done on the left uterus (Figure 1) to delivery male alive neonate weighing 2400 grams with APGAR scores of 7 and 9 at $1^{\text {st }}$ and $5^{\text {th }}$ minute respectively.

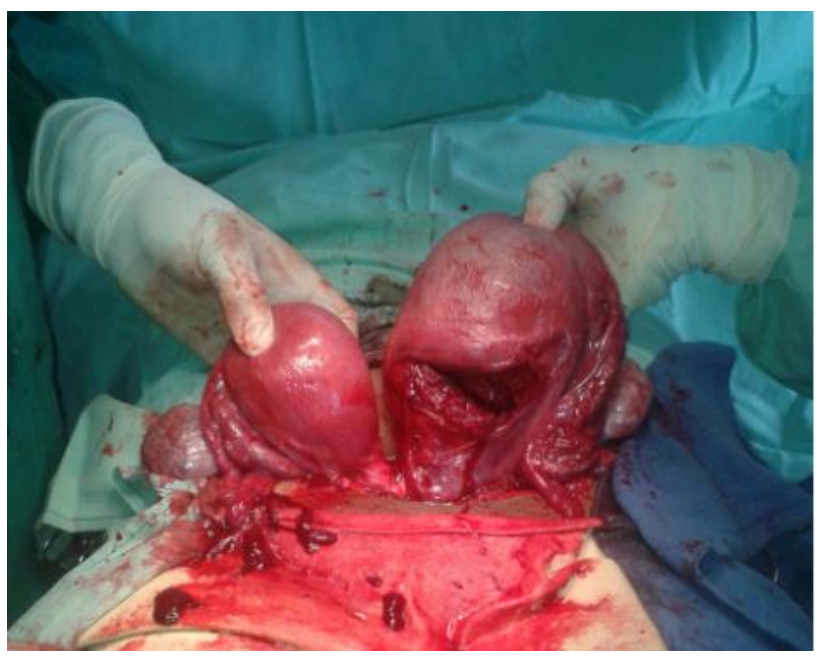

Figure 1: Didelphic uterus at cesarean section each with one ovary and tube at Gimbi Adventist Hospital, West Wollega, Ethiopia, January 2015.

After the operation, digital speculum examination revealed two cervices. On $4^{\text {th }}$ post-operative day, abdominal ultrasound was done by radiographer and there were no renal pathologies identified.

The mother and newborn discharged on $5^{\text {th }}$ post-operative day with good condition.

\section{DISCUSSION}

Congenital uterine anomalies occur during embryonic life. They are often asymptomatic and therefore unrecognized $^{1,2}$ like our patient who presented to the hospital, for the first time in pregnancy, with fetal malpresentation. Didelphic uteri are often associated with increased risk of premature labor, abnormal presentations with dystocia, and the increased necessity for cesarean section. ${ }^{8}$ This patient had breech presentation during both pregnancies. This increased mal-presentation rate might explain the increased cesarean section rate in uterine didelphys. During previous delivery this anomaly was not recognized as it was uneventful breech vaginal delivery. Therefore recurrent breech presentation may be a clue for the diagnosis of uterine didelphys.

The didelphic uterus, because of reduced volume in each duplicated segment, has a poor reproductive outcome with a $20-30 \%$ chance of carrying pregnancy to term. ${ }^{9,10}$ However, our patient had two successful pregnancies. Both pregnancies were complicated by breech presentation and preeclampsia. 
What is striking in this patient was the presence of preeclampsia in this and previous pregnancies. This issue may raise the question whether uterine malformations predispose pregnant mothers for hypertensive disorders of pregnancy or not.

Though didelphic uterus is associated urinary tract anomalies ${ }^{6,7}$ our patient had normal abdominal ultrasound finding.

\section{CONCLUSION}

In conclusion, uterine didelphys can have silent clinical presentation prior to pregnancy and thus it is important to have high index of suspicion of didelphic uterus when term pregnancy is complicated by recurrent breech presentation.

\section{ACKNOWLEDGMENTS}

The author thanks Gimbi Adventist hospital for allowing him to publish this case report.

Funding: No funding sources Conflict of interest: None declared

Ethical approval: Not required

\section{REFERENCES}

1. Ali Hassan, H. Osman, A. Algyoum, A. Rahim, A. Abd Elrahim, A. Elzaki. Case of double uterus using imaging technique. Sch J Med Case Rep. 2014;2(11):711-4.

2. Grimbizis GF, Camus M, Tarlatzis BC, Bontis JN, Devroey P. Clinical implications of uterine malformations and hysteroscopic treatment results. Hum Reprod Update. 2001 Mar-Apr;7(2):161-74.

3. Ronald E. Iverson, Alan H. DeCherney, Marc R. Laufer. Clinical manifestations and diagnosis of congenital anomalies of the uterus. Up-To-Date. 2012;20(3):1-4.

4. Gul F, Jabeen M. Double uterus: a case report. KUST Med J. 2010;2(1):27-9.

5. Andrew F. Hundley, Julia R. Fielding, Lennox Hoyte. Double cervix and vagina with septate uterus: an uncommon Müllerian malformation. Obstet Gynecol. 2001 Nov;98(5 Pt 2):982-5.

6. Barbara Hoffman, John Schorge, Joseph Schaffer, Lisa Halvorson, Karen Bradshaw, F. Cunningham. Williams gynecology: anatomic disorders, section 2. In: Barbara Hoffman, John Schorge, Joseph Schaffer, Lisa Halvorson, Karen Bradshaw, F. Cunningham, eds. 1st ed. New York: McGraw-Hill Companies; 2008.

7. Hansa Dhar, Yasser A. Razek, Ilham Hamdi. Uterus didelphys with obstructed right hemivagina, ipsilateral renal agenesis and right pyocolpos: a case report. Oman Med J. 2011;26(6):447-50.

8. Ruchika Garg, Anita Kwatra, V. B. Bangal. Rare case of uterus didelphis with full term pregnancy in each horn. Pravara Med Rev. 2010;2(4):22-4.

9. Fliegner JR. Uncommon problems of the double uterus. Med J Aust. 1986;145(10):510-2.

10. Aher Gautam S, Gavali Urmila G, Kulkarni Meghana. Uterine didelphys with cervical incompetence. Int $\mathrm{J}$ Med Res Health Sci. 2013;2(2):281-3.

DOI: $10.18203 / 2320-1770 . i j r \operatorname{cog} 20150109$

Cite this article as: Bekabil TT. Recurrent preeclampsia and breech presentation in term pregnancy: the case of didelphic uterus. Int J Reprod Contracept Obstet Gynecol 2015;4:855-8. 